\title{
The whole woman: Sex and gender differences in variation
}

\author{
Penelope ECKert \\ University of Illinois, Chicago \\ and \\ Institute for Research on Learning, Palo Alto
}

\section{ABSTRACT}

\begin{abstract}
Speaker's sex has emerged as one of the most important social factors in the quantitative study of phonological variation. However, sex does not have a uniform effect on variables or even on variables that represent sound change in progress. This is because sex is not directly related to linguistic behavior but reflects complex social practice. The correlations of sex with linguistic variables are only a reflection of the effects on linguistic behavior of gender - the complex social construction of sex-and it is in this construction that one must seek explanations for such correlations. Sociolinguists generally treat sex in terms of oppositional categories (male/female), and the effects of sex on variation are generally sought in linguistic differences between male and female speakers. However, because gender differences involve differences in orientation to other social categories, the effects of gender on linguistic behavior can show up in differences within sex groupings. Data on sound changes in progress (the Northern Cities Chain Shift) among Detroit area adolescents show that gender has a variety of effects on variables and that the significance of gender in variation cannot be reduced to notions of male or female speech as "more or less conservative."
\end{abstract}

The tradition of large-scale survey methodology in the study of variation has left a gap between the linguistic data and the social practice that yields these data. Since sociolinguistic surveys bring away little information about the communities that produce their linguistic data, correlations of linguistic variants with survey categories have been interpreted on the basis of general knowledge of the social dynamics associated with those categories. The success of this approach has depended on the quality of this general knowledge. The examination of variation and socioeconomic class has benefited from sociolinguists' attention to a vast literature on class and to critical analyses of the indices by which class membership is commonly determined. The study of gender and variation, on the other hand, has suffered from the fact that

This work was supported by the Spencer Foundation and the National Science Foundation (BNS 8023291). I owe a great debt of thanks to David Sankoff for his very generous and important help with this article. The value of his suggestions for strengthening both the conception and the presentation of these arguments is immeasurable. 
the amount of scientific attention given to gender over the years cannot begin to be compared with that given to class. Many current beliefs about the role of gender in variation, therefore, are a result of substituting popular (and unpopular) belief for social theory in the interpretation of patterns of sex correlations with variation.

Sociolinguists are acutely aware of the complex relation between the categories used in the socioeconomic classification of speakers and the social practice that underlies these categories. Thus, we do not focus on the objectivized indices used to measure class (such as salary, occupation, and education) in analyzing correlations between linguistic and class differences, even when class identification is based on these indices. Rather, we focus more and more on the relation of language use to the everyday practice that constitutes speakers' class-based social participation and identity in the community. Thus, explanations take into consideration interacting dynamics such as social group and network membership (Labov, 1972b; Milroy, 1980), symbolic capital and the linguistic marketplace (Bourdieu \& Boltanski, 1975; Sankoff \& Laberge, 1978; Thibault, 1983), and local identity (Labov, 1972c, 1980). The same can be said to some extent of work on ethnicity and variation, where researchers have interpreted data on ethnic differences in variation in terms of complex interactions between ethnicity, group history, and social identity (Horvath \& Sankoff, 1987; Labov, 1972b; Laferriere, 1979). The study of the sociolinguistic construction of the biological categories of age and sex, on the other hand, has so far received less sophisticated attention (Eckert, Edwards, \& Robins, 1985). The age continuum is commonly divided into equal chunks with no particular attention to the relation between these chunks and the life stages that make age socially significant. Rather, when the full age span is considered in community studies, the age continuum is generally interpreted as representing continuous apparent time. At some point, the individual's progress through normative life stages (e.g., school, work, marriage, childrearing, retirement) might be considered rather than, or in addition to, chronological age. Some work has explored the notion of life stage. The very apparent lead of preadolescents and adolescents in sound change has led some researchers to separate those groups in community studies (Macaulay, 1977; Wolfram, 1969), and some attention has been focused on the significance of these life stages in variation (Eckert, 1988; Labov, 1972b). There has also been some speculation about changes of speakers' relation to the linguistic marketplace in aging (Eckert, 1984; Labov, 1972a; Thibault, 1983). Most interestingly, there have been examinations of the relation of age groups to historical periods of social change in the community (Clermont \& Cedergren, 1978; Laferriere, 1979). But taken together, these studies are bare beginnings and do not constitute a reasoned and coherent approach to the sociolinguistic significance of biological age.

Like age, sex is a biological category that serves as a fundamental basis for the differentiation of roles, norms, and expectations in all societies. It is these roles, norms, and expectations that constitute gender, the social construction of sex. Although differences in patterns of variation between men 
and women are a function of gender and only indirectly a function of sex (and, indeed, such gender-based variation occurs within, as well as between, sex groups), we have been examining the interaction between gender and variation by correlating variables with sex rather than gender differences. This has been done because although an individual's gender-related place in society is a multidimensional complex that can only be characterized through careful analysis, his or her sex is generally a readily observable binary variable, and inasmuch as sex can be said to be a rough statistical indication of gender, it has been reasonable to substitute the biological category for the social in sampling. However, because information about the individual's sex is easily accessible, data can be gathered without any inquiry into the construction of gender in that community. As a result, since researchers have not had to struggle to find the categories in question, they tend to fall back on unanalyzed notions about gender to interpret whatever sex correlations emerge in the data and not to consider gender where there are no sex correlations.

Gender differences are exceedingly complex, particularly in a society and era where women have been moving self-consciously into the marketplace and calling traditional gender roles into question. Gender roles and ideologies create different ways for men and women to experience life, culture, and society. Taking this as a basic approach to the data on sex differences in variation, there are a few assumptions one might start with. First, and perhaps most important, there is no apparent reason to believe that there is a simple, constant relation between gender and variation. Despite increasingly complex data on sex differences in variation, there remains a tendency to seek a single social construction of sex that will explain all of its correlations with variation. This is reflected in the use of a single coefficient for sex effects in variable rule or regression analyses of variation. This perspective limits the kind of results that can be obtained, since it is restricted to confirming the implicit hypothesis of a single type of sex effect or, worse, to indicating that there is no effect at all. Second, we must carefully separate our interpretation of sex differences in variation from artifacts of survey categories. I would argue that sociolinguists tend to think of age and class as continua and gender as an opposition, primarily because of the ways in which they are determined in survey research. But just as the class effect on variation may be thought of in terms of the binary bourgeois-working class opposition (Rickford, 1986), and just as there is reason to believe that the age continuum is interrupted by discontinuities in the effects of different life stages on people's relation to society and, hence, on language, variation based on gender may not always be adequately accounted for in terms of a binary opposition.

INTERPRETATIONS OF SEX DIFFERENCES IN VARIATION

There is a general misconception among writers who do not deal directly with variation that women's speech is more conservative than men's. Indeed, women do tend to be more conservative than men in their use of those ver- 
nacular forms that represent stable social variables. On the other hand, the very earliest evidence on variation (Gauchat, 1905) showed women leading in sound change, a finding that has been repeated in Labov's work in New York City (1966) and Philadelphia (1984), in Cedergren's work in Panama (1973), and in my own work in the Detroit suburbs. If these trends were universal, the coefficient of the sex variable $(1=$ female, $0=$ male $)$ in a variable rule or regression analysis of variation would always have positive sign for changes in progress and negative sign for stable variables.

But the picture is not quite as simple as this generalization suggests. First of all, men do lead in some sound changes. Trudgill found men leading in most changes in Norwich (1972a), and Labov (1972c) found men leading in some changes in Martha's Vineyard (1972) and Philadelphia (1984). Thus, there is every reason to assume that sex differences may vary from one variable to another. As Labov argued (1984), one might expect different sex correlations with old or new changes, for instance. This could still all be represented by a single sex effect in a statistical analysis, but the sign of the effect would depend on the particular variable. Second, sex does not have the same effect on language use everywhere in the population. Women's overall lead in the population could hide a variety of complex patterns among other social parameters, the simplest of which would be a sexual crossover along the socioeconomic hierarchy. Labov found just such a pattern in Philadelphia, for several vowels, with women leading at the lower end of the socioeconomic hierarchy and lagging at the upper end. Statistical analyses in these contexts require more than a single sex effect; either an interaction should be included or separate analyses done for women and men. Not only is it a mistake to claim that women are more or less innovative than men, but at this point in our research it is a mistake to claim any kind of constant constraint associated with gender. It is, above all, this mistake that characterizes much current work on sex differences in variation. It is commonplace for sociolinguists to allow the gender categories that they use to classify speakers (i.e., male vs. female) to guide their thinking about the effects of gender in variation. In particular, men and women are perceived as categorically different, indeed opposite and opposed, in their use of linguistic variables.

\section{HIE R A R C H Y}

Labov's (1966) original findings in New York City clearly lined up socioeconomic class, style, sound change, prestige, and evaluation on a single axis. The hierarchical socioeconomic continuum is also a continuum of linguistic change, wherein extent of historical change correlates inversely with socioeconomic status. At any place along this continuum, speech style reproduces this continuum, with each speaker's stylistic continuum from more casual to more careful speech reflecting a segment of the socioeconomic continuum. A causal connection between the two is based on the assumption that speakers 
look upward in the socioeconomic hierarchy for standards of correctness and feel constrained in their formal interactions to "accommodate" upward. Thus, there is a folk connection between old and new, formal and informal, better and worse, correct and incorrect. The notion of conservatism in language, then, takes on a simultaneously historical and social meaning. Finally, responses to matched guise tests confirm that members of the community associate the use of linguistic variables with individuals' worth in the marketplace. With this overwhelming stratificational emphasis in the study of variation, sex differences in behavior placed along this continuum are seen in relation to it; hence, when men and women differ in their use of sound change, this tends to be explained in terms of their different orientation to class.

Labov and Trudgill have both emphasized a greater orientation to community prestige norms as the main driving force in women's, as opposed to men's, linguistic behavior. Trudgill's findings in Norwich led him to see women as overwhelmingly conservative, as they showed men leading in most change. Furthermore, women in his sample tended to overreport their use of prestige forms and men tended to underreport theirs. He therefore argued that women and men respond to opposed sets of norms: women to overt, standard-language prestige norms and men to covert, vernacular prestige norms. Overt prestige attaches to refined qualities, as associated with the cosmopolitan marketplace and its standard language, whereas covert prestige attaches to masculine, "rough and tough" qualities. Trudgill (1972b:182-183) speculated that women's overt prestige orientation was a result of their powerless position in society. He argued that inasmuch as society does not allow women to advance their power or status through action in the marketplace, they are thrown upon their symbolic resources, including language, to enhance their social position. This is certainly a reasonable hypothesis, particularly since it was arrived at to explain data in which women's speech was overwhelmingly conservative. However, what it assumes more specifically is that women respond to their powerlessness by developing linguistic strategies for upward mobility, that is, that the socioeconomic hierarchy is the focus of social strategies. There are alternative views of exactly what social strategies are reflected in women's conservatism. An analysis that emphasizes the power relations implicit in the stratificational model was put forth by Deuchar (1988), who argued that women's conservative linguistic behavior is a function of basic power relations in society. Equating standard speech with politeness, she built on Brown's (1980) and Brown and Levinson's (1987) analyses of politeness as a face-saving strategy, arguing that the use of standard language is a mechanism for maintaining face in interactions in which the woman is powerless.

I would argue that elements of these hypotheses are correct but that they are limited by the fact that they are designed to account for one aspect of women's linguistic behavior only: those circumstances under which women's language is more conservative than men's. Based on the multiple patterns of 
sex, class, and age difference that he found in Philadelphia sound changes in progress, Labov (1984) sought to explain why women are more conservative in their use of stable variables but less conservative in their use of changes in progress and why women lead men in some changes and not in others. Although his data do not show women being particularly conservative, he based his analysis on the assumption that women's linguistic choices are driven by prestige. What he sought to explain, therefore, are cases where women's behavior is not conservative. Based on his Philadelphia data, Labov argued that women lag in the use of variants that are stigmatized within the larger community, that is, stable sociolinguistic variables and changes in progress that are sufficiently old and visible as to be stigmatized within the larger community. Women's behavior in these cases, then, is driven by global prestige norms. At the same time, women lead in changes that are still sufficiently limited to the neighborhood and local community to carry local prestige without having attracted a stigma in the larger Philadelphia community. In this case, Labov argued, women's behavior is driven by local prestige norms. If this explanation accounts for the Philadelphia data, it does not cover the New York City cases of (aeh) and (oh) (Labov, 1966), where women led in sound changes that had grown old and stigmatized. But more important, I can see no independent reason to seek explanations for women's behavior in prestige.

It is important to note at this point that three kinds of prestige have been put forth so far: (a) global prestige, based on norms imposed in the standard language marketplace; (b) covert prestige, based on opposition to those norms; and (c) local prestige, based on membership in the local community. Although the notion of covert prestige has come under attack, and conflated by some with local prestige, I have argued that all three of these forces play a role in variation (Eckert, 1989b). Later in this article, I suggest that not prestige but power is the most appropriate underlying sociological concept for the analysis of gender-based linguistic variation.

\section{SEX DIFFERENCES AS OPPOSITION}

If the focus on class as a continuum has led to the interpretation of sex differences in speech as differences in orientation to the class hierarchy, the focus on sex as a two-way opposition has led also to interpreting sex differences as sex markers. Brown and Levinson (1979) argued against the treatment of sociolinguistic variables as markers, pointing out that the correlations may well be masking intervening variables. Although much work on phonological variation does not explicitly refer to variables as markers, the view of variables as markers is implicit when linguists attribute individuals' use or nonuse of a variable to a desire to stress or deny membership in the category with which it is being correlated at the moment. Related to the view of sex differences as markers is the oppositional view of gender differences in variation $-\mathrm{a}$ reification of a particular view of gender deriving from 
the ease of identifying individuals' sex category membership and reflecting the common expression "the opposite sex." Two instances can serve as examples in relation to gender.

Hindle (1979) examined one female speaker's use of variables in three situations: at work, at the dinner table with her husband and a friend (Arvilla Payne, the fieldworker), and in a weekly all-women's card game. Based on an assumption that speakers will implement vernacular sound changes more in egalitarian situations than in hierarchical ones, Hindle's initial hypothesis was that the speaker would show more extreme (vernacular) forms at the dinner table with her husband and a friend, because he believed social relations in that setting to be less hierarchical than in the other settings. As it turned out, she showed more advanced change in the card game. One might argue that this does not disprove Hindle's underlying assumption, that speakers show more vernacular variants in more egalitarian situations, since there is reason to believe that relations among a group of women playing cards on a weekly basis are less hierarchical than those between a husband and wife - perhaps particularly in the presence of a third person. However, he chose to attribute the use of extreme variants in a change, in which women lead community-wide, to accommodation to the group of women.

The theory of accommodation depends on the notion of marker, and this explanation essentially asserts that the speaker's use of the change among women was an attempt to mark herself as a fellow woman. One might consider, however, that her enhanced use of this phonological change at the card game is related to an affirmation of -indeed, perhaps a competition among equals for - some aspect of social identity that has nothing at all to do with gender. In other words, that these women are together in a particular set of social relationships that happen among women encourages them to emphasize some aspect of their social identities.

Whereas Hindle has attributed this woman's extreme use of a sound change to accommodation to women, others have attributed similar behavior to differentiation from men. Tony Kroch has argued that the curvilinear pattern frequently found in the socioeconomic stratification of linguistic variables is due to male speech only. Specifically, he speculated that if the sexes are examined separately, women's speech will show a linear pattern, reflecting the regular spread of sound change upward from the lowest socioeconomic group. The curvilinear pattern, then, is the result of a sudden drop in the use of extreme variables by men in the lowest socioeconomic group in relation to the adjacent higher group. This drop, according to Kroch, is the result of an avoidance on the part of men in this socioeconomic group of what they perceive as a female speech pattern. Labov (1984) found the pattern that Kroch predicted for the raising of the nucleus in Philadelphia (aw) (Figure 1), and Guy, Horvath, Vonwiller, Daisley, and Rogers (1986) found it for the Australian Question Intonation (Figure 2).

If one were prepared to accept this argument, Guy et al.'s data are more convincing than Labov's. However, in both cases, one could argue that it is 


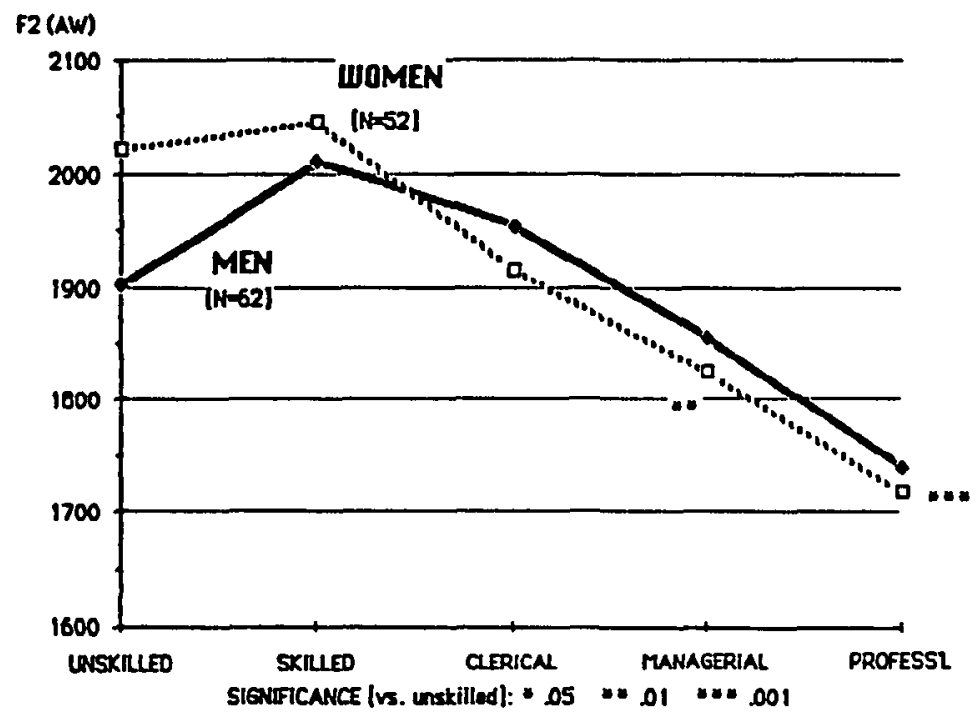

FIGURE 1. Occupation coefficients for F2 of (aw) for men and women in Philadelphia neighborhoods (from Labov, 1984).

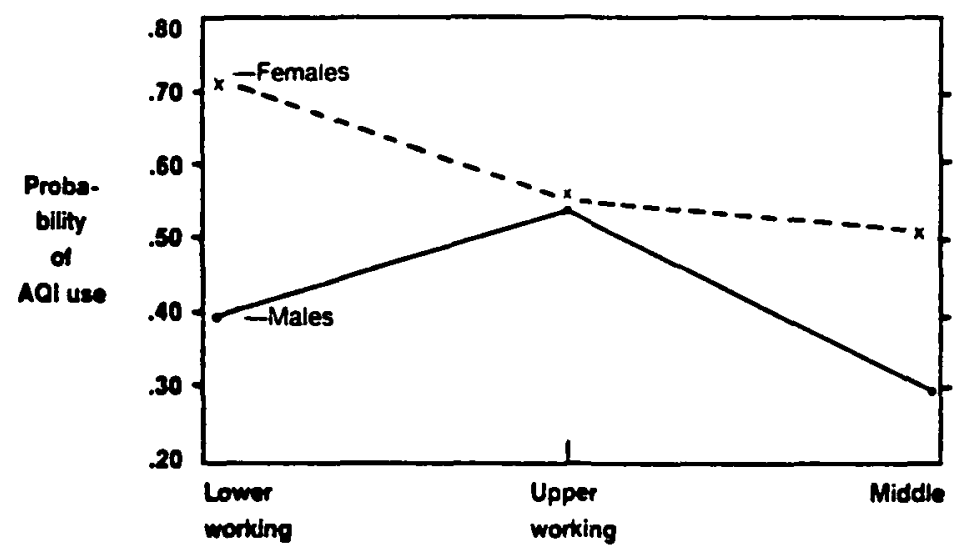

\section{Socisl clase}

FIGURE 2. Probability of Australian Question Intonation use by class and sex (from Guy et al., 1986:37).

only the lower working-class men's divergence from a linear pattern that creates enough of a woman's lead for it to acquire significance. In the case of Philadelphia (aw), aside from the working-class men's sudden downturn in use, the men lead the women in change in all socioeconomic groups. In the 
case of Australian Question Intonation, although the women lead in the middle class, there is virtually no sex difference in the upper working class. The lower working-class men's perception of the pattern, then, would have to be based on the speech of women at a considerable social remove-a remove that itself could be as salient as the sex difference. I venture to believe that if the pattern had been the other way around, with the lower working-class women showing the downturn, the typical explanation would have attributed their conservatism to prestige factors and upward mobility. I seriously doubt that these men's motivation for conservatism is upward mobility, just as I doubt upward mobility as an explanation for women's conservatism. But above all, it is problematic to seek the explanation of their behavior in simple differentiation from the "opposite" sex group.

I do not mean to argue that speakers never associate specific variables with gender, nor would I argue that there are no cases in which men or women avoid variables that they perceive as inappropriately gender marked. I would not even argue against the claim that men are more likely to avoid such variables than women, since there are greater constraints on men to be genderappropriate in certain symbolic realms. However, I believe that variables that function as something like gender markers must have some iconic value. The Arabic palatalization discussed by Haeri (1989) is a candidate for such a variable, although that case also points to intervening variables (Haeri, personal communication). But, as Brown and Levinson (1979) pointed out, a correlation with a particular social category may mask some other attribute that is also associated with that category. One that comes easily to mind in relation to gender is power. This could clearly apply in the case of Australian Question Intonation. Guy et al. (1986) described this intonation pattern as a confirmation-seeking strategy, which one can assume is associated with subordination regardless of sex (Baroni \& d'Urso, 1984).

What I will argue is that gender does not have a uniform effect on linguistic behavior for the community as a whole, across variables, or for that matter for any individual. Gender, like ethnicity and class and indeed age, is a social construction and may enter into any of a variety of interactions with other social phenomena. And although sociolinguists have had some success in perceiving the social practice that constitutes class, they have yet to think of gender in terms of social practice.

There is one important way in which gender is not equivalent to categories like class or ethnicity. Gender and gender roles are normatively reciprocal, and although men and women are supposed to be different from each other, this difference is expected to be a source of attraction. Whereas the power relations between men and women are similar to those between dominant and subordinate classes and ethnic groups, the day-to-day context in which these power relations are played out is quite different. It is not a cultural norm for each working-class individual to be paired up for life with a member of the middle class or for every black person to be so paired up with a white person. However, our traditional gender ideology dictates just this 
kind of relationship between men and women. If one were to think of variables as social markers, then, one might expect gender markers to behave quite differently from markers of class or ethnicity. Whereas the aggressive use of ethnic markers (i.e., frequent use of the most extreme variants) is generally seen as maintaining boundaries - as preventing closeness - between ethnic groups, the aggressive use of gender markers is not. By the same token, the aggressive use of gender markers is not generally seen as a device for creating or maintaining solidarity within the category. To the extent that masculine or feminine behavior marks gender, its use by males and females respectively is more a device for competing with others in the same category and creating solidarity with those in the other category, and aggressive crosssex behavior is seen as designed to compete with members of the other sex for the attention of members of the same sex.

Two other things follow from the specialization of gender roles, which may apply also to other kinds of differences such as ethnicity.

1. To the extent that male and female roles are not only different but reciprocal, members of either sex category are unlikely to compete with (i.e., evaluate their status in relation to) members of the other. Rather, by and large, men perceive their social status in relation to other men, whereas women largely perceive their social status in relation to other women.' Thus, differentiation on the basis of gender might well be sought within, rather than between, sex groups.

2. Men and women compete to establish their social status in different ways, as dictated by the constraints placed on their sex for achieving status. This is particularly clear where gender roles are separate, and in fact when people do compete in the role domain of the other sex, it is specifically their gender identity that gets called into question.

POWER, STATUS, AND OTHER THINGS

All of the currently leading hypotheses about the effects of gender on variation recognize, however implicitly, that linguistic differences are a result of men's and women's place in society at a particular time and place. What differs in these hypotheses is the specificity and the depth of the causes in society and, hence, their changeability over time and from community to community.

Milroy (1980) traced sex differences in the use of vernacular variables to differences in the nature of men's and women's social networks-differences that are themselves a result of material factors. Based on the understanding that dense, multiplex, locally based social networks enforce the use of vernacular variables, Milroy argued that where economic circumstances allow women to form such networks, their speech takes on the characteristics of men's speech under the same conditions. In this case, then, the explanation for $\mathrm{se}_{\wedge}$ differences in variation does not lie in differences between men's and 
women's fundamental relations or orientation to society per se, but in the differences in the circumstances in which they normally find themselves. Closely related to the dynamics invoked by Milroy, particularly to the importance of work patterns on the nature of social networks and to social forces behind the use of vernacular or standard language, is the notion of marketplace. Nichols (1983) showed that differences between women as well as between women and men can be a function of their access to jobs that determine their participation in the standard language marketplace (Sankoff \& Laberge, 1978). Both Milroy's and Nichols' examples suggest that it is the configuration of contact and interaction created by economic conditions that ultimately determines individuals' linguistic patterns, and in both cases the linguistic patterns may be as changeable as the economic conditions that underlie them.

The purpose of these analyses is to show that gender differences in variation are attributable to social forces that attach to women by virtue of their place in the economy. And whereas common sense supports this view, it is also evident that although employment conditions may change, the underlying relations of power and status between men and women can remain quite unchanging. So whereas economic explanations focus on the marketplace, they attribute gender differences in language to social forces that could presumably continue to operate on the individual speaker regardless of his or her personal relation to the economy. Since actual power relations between men and women can be expected to lag behind (indeed perhaps be orthogonal to) changes in relative positions in the marketplace, one can expect such a dynamic in language to outlive any number of economic changes. One might argue that the socioeconomic hierarchy, in this case, is the least of women's problems, since their powerless position is brought home to them, in a very real sense, in every interaction. Women's inequality is built into the family, and it continues in the workplace, where women are constantly confronted with a double bind, since neither stereotypic female nor stereotypic male behavior is acceptable. Thus, one might expect that some gender differences in language are more resistant to small-scale economic differences. In particular, the common claim that women are more expressive with language (Sattel, 1983) resides in deeper differences than the vagaries of the local economy.

The domestication of female labor - according to Marx, one of the earliest manifestations of the division of labor - involves a strict division of roles, with men engaged in the public marketplace and women's activities restricted to the private, domestic sphere (Elshtain, 1981; Sacks, 1974). The man competes for goods and power in the marketplace in the name of the family and controls these within the family. Thus, although the woman is solely responsible for maintaining the domestic unit, she has no direct control over that unit's capital. Although a man's personal worth is based on the accumulation of goods, status, and power in the marketplace, a woman's worth is based on her ability to maintain order in, and control over, her domestic 
realm. Deprived of power, women can only gain compliance through the indirect use of a man's power or through the development of personal influence.

Since to have personal influence without power requires moral authority, women's influence depends primarily on the painstaking creation and elaboration of an image of the whole self as worthy of authority. Thus, women are thrown into the accumulation of symbolic capital. This is not to say that men are not also dependent on the accumulation of symbolic capital, but that symbolic capital is the only kind that women can accumulate with impunity. And, indeed, it becomes part of their men's symbolic capital and hence part of the household's economic capital. Whereas men can justify and define their status on the basis of their accomplishments, possessions, or institutional status, women must justify and define theirs on the basis of their overall character. This is why, in peasant communities as in working-class neighborhoods, the women who are considered local leaders typically project a strong personality and a strong, frequently humorous, image of knowing what is right and having things under control.

When social scientists say that women are more status conscious than men, and when sociolinguists pick this up in explaining sex differences in speech, they are stumbling on the fact that, deprived of power, women must satisfy themselves with status. It would be more appropriate to say that women are more status-bound than men. This emphasis on status consciousness suggests that women only construe status as being hierarchical (be it global or local hierarchy) and that they assert status only to gain upward mobility. But status is not only defined hierarchically; an individual's status is his or her place, however defined, in the group or society. It is this broader status that women must assert by symbolic means, and this assertion will be of hierarchical status when a hierarchy happens to be salient. An important part of the explanation for women's innovative and conservative patterns lies, therefore, in their need to assert their membership in all of the communities in which they participate, since it is their authority, rather than their power in that community, that assures their membership. Prestige, then, is far too limited a concept to use for the dynamics at work in this context.

Above all, gender relations are about power and access to property and services, and whatever symbolic means a society develops to elaborate gender differences (such as romance and femininity) serve as obfuscation rather than explanation. Whenever one sees sex differences in language, there is nothing to suggest that it is not power that is at issue rather than gender per se. The claim that working-class men's speech diverges from working-class women's speech in an effort to avoid sounding like women reflects this ambiguity, for it raises the issue of the interaction between gender and power. Gender differentiation is greatest in those segments of society where power is the scarcest - at the lower end of the socioeconomic hierarchy, where women's access to power is the greatest threat to men. There is every reason to believe that the lower working-class men's sudden downturn in the use of 
Australian Question Intonation shown in Guy et al. (1986) is an avoidance of the linguistic expression of subordination by men in the socioeconomic group that can least afford to sound subordinate.

For similar reasons of power, it is common to confuse femininity and masculinity with gender, and perhaps nowhere is the link between gender and power clearer. Femininity is a culturally defined form of mitigation or denial of power, whereas masculinity is the affirmation of power. In Western society, this is perhaps most clearly illustrated in the greater emphasis on femininity in the south, where regional economic history has domesticized women and denied them economic power to a greater degree than it has in the industrial north (Fox-Genovese, 1988). The commonest forms of femininity and masculinity are related to actual physical power. Femininity is associated with small size, clothing and adornment that inhibit and/or do not stand up to rough activity, delicacy of movement, quiet and high pitched voice, friendly demeanor, politeness. The relation between politeness and powerlessness has already been emphasized (Brown, 1980) and surfaces in a good deal of the literature on gender differences in language. Although all of these kinds of behavior are eschewed by men at the lower end of the socioeconomic hierarchy, they appear increasingly in male style as one moves up the socioeconomic hierarchy until, in the upper class, what is called effeminacy may be seen as the conscientious rejection of physical power by those who exercise real global power (Veblen, 1931) by appropriating the physical power of others.

The methodological consequences of these considerations is that we should expect to see larger differences in indications of social category membership among women than among men. If women are more constrained to display their personal and social qualities and memberships, we would expect these expressions to show up in their use of phonological variables. This necessitates either a careful analysis of statistical interaction, or separate analysis of the data from each gender group, before any comparison.

\section{GENDER AND ADOLESCENT SOCIAL CATEGORIES}

In this section, I discuss some evidence from adolescent phonological variation to illustrate the complexity of gender in the social scheme of things. Adolescents are quite aware of the gender differences I have discussed, particularly since they are at a life stage in which the issue of gender roles becomes crucial. By the time they arrive in high school, adolescent girls (particularly those who have been tomboys) are getting over the early shock of realizing that they do not have equal access to power. One girl told me of the satisfaction it still gives her to think back to the time in elementary school when she and her best friend beat up the biggest male bully in their class and of the difficult adjustment it had been to finding less direct means of controlling boys. In fact, she was very attractive and was aware but not partic- 
ularly pleased that her power in adolescence to snub troublesome males was as great as her past power to beat them up.

Whether or not they wielded any direct power in their childhoods, adolescent girls know full well that their only hope is through personal authority. In secondary school, this authority is closely tied up with popularity (Eckert, 1989a, 1990), and as a result, girls worry about and seek popularity more than boys. And although boys are far from unconcerned about popularity, they need it less to exert influence. For a boy can indeed gain power and status through direct action, particularly through physical prowess. Thus, when they reach high school, most girls and boys have already accepted to some extent that they will have different routes to social status. In many important ways, boys can acquire power and status through the simple performance of tasks or display of skills. A star varsity athlete, for instance, regardless of his character or appearance, can enjoy considerable status. There is virtually nothing, however, that a girl lacking in social or physical gifts can do that will accord her social status. In other words, whereas it is enough for a boy to have accomplishments of the right sort, a girl must be a certain sort of person. And just as the boy must show off his accomplishments, the girl must display her persona. One result of this is that girls in high school are more socially constrained than boys. Not only do they monitor their own behavior and that of others more closely, but they maintain more rigid social boundaries, since the threat of being associated with the wrong kind of person is far greater to the individual whose status depends on who she appears to be rather than what she does. This difference plays itself out linguistically in the context of class-based social categories.

Two hegemonous social categories dominate adolescent social life in American public high schools (Eckert, 1989a). These categories represent opposed class cultures and arise through a conflict of norms and aspirations within the institution of the school. Those who participate in school activities and embrace the school as the locus of their social activities and identities constitute, in the high school, a middle-class culture. In the Detroit area, where the research I report on was done, members of this category are called "Jocks" whether or not they are athletes, and they identify themselves largely in opposition to the "Burnouts." Burnouts, a working-class culture oriented to the blue collar marketplace, do not accept the school as the locus of their operations; rather, they rebel to some extent against school activities and the authority they represent and orient themselves to the local, and the neighboring urban, area. The Burnouts' hangouts are local parks, neighborhoods, bowling alleys, and strips. They value adult experience and prerogatives and pursue a direct relation with the adult community that surrounds them. The school mediates this relation for the Jocks, on the other hand, who center their social networks and activities in the school. The Jocks and the Burnouts have very different means of acquiring and defining the autonomy that is so central to adolescents. Whereas the Jocks seek autonomy in adult-like roles in the corporate context provided by the school institution, the Burnouts seek it in direct relations with the adult resources of the local area. 
Within each category, girls and boys follow very different routes to achieve power and status. The notion of resorting to the manipulation of status when power is unavailable is in fact consciously expressed in the adolescent community. Girls complain that boys can do real things, whereas boys complain that girls talk and scheme rather than doing real things. By "real" things, they mean those things that reflect skills other than the purely social and that reflect personal, and specifically physical, prowess. Boys are freer in general. For example, Burnout boys can go to Detroit alone, whereas girls must go under their protection; this seriously curtails a Burnout girl's ability to demonstrate urban autonomy. The Jock boys can also assert their personal autonomy through physical prowess. Although it is not "cool" for a Jock boy to fight frequently, the public recognition that he could is an essential part of his Jock image. In addition, Jock boys can gain public recognition through varsity sports on a level that girls cannot. Thus, the girls in each social category must devote a good deal of their activity to developing and projecting a "whole person" image designed to gain them influence within their own social category. The female Jocks must aggressively develop a Jock image, which is essentially friendly, outgoing, active, clean-cut, allAmerican. The female Burnouts must aggressively develop a Burnout image, which is essentially tough, urban, "experienced." As a result, the symbolic differences between Jocks and Burnouts are clearly more important for girls than for boys. In fact, there is less contact between the two categories among girls, and there is far greater attention to maintaining symbolic differences on all levels - in clothing and other adornment, in demeanor, in publicly acknowledged substance use and sexual activity. There is, therefore, every reason to predict that girls also show greater differences than boys in their use of any linguistic variable that is associated with social category membership or its attributes.

I have shown elsewhere that the most extreme users of phonological variables in my adolescent data are those who have to do the greatest amount of symbolic work to affirm their membership in groups or communities (Eckert, 1989b). Those whose status is clearly based on "objective" criteria can afford to eschew symbolization. It does not require much of a leap of reasoning to see that women's and men's ways of establishing their status would lead to differences in the use of symbols. The constant competition over externals, as discussed in Maltz and Borker (1982), would free males from the use of symbols. Women, on the other hand, are constrained to exhibit constantly who they are rather than what they can do, and who they are is defined with respect primarily to other women.

PHONOLOGICAL VARIATION

The following data on phonological variation among Detroit suburban adolescents provide some support for the discussion of the complexity of gender constraints in variation. The data were gathered in individual sociolin- 


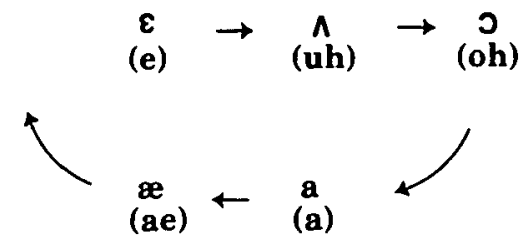

FIGURE 3. The Northern Cities Chain Shift.

guistic interviews during 2 years of participant observation in one high school in a suburb of Detroit. During this time, I followed one graduating class through its last 2 years of high school, tracing social networks and examining the nature of social identity in this adolescent community. The school serves a community that is almost entirely white, and although the population includes a variety of eastern and western European groups, ethnicity is downplayed in the community and in the school and does not determine social groups. The community covers a socioeconomic span from lower working class through upper middle class, with the greatest representation in the lower middle class.

The speakers in the Detroit area are involved in the Northern Cities Chain Shift (Labov, Yaeger, \& Steiner, 1972), a pattern of vowel shifting involving the fronting of low vowels and the backing and lowering of mid vowels (Figure 3). The older changes in this shift are the fronting of (ae) and (a), and the lowering and fronting of (oh). The newer ones are the backing of (e) and (uh).

The following analysis is based on impressionistic phonetic transcription of the vocalic variables from taped free-flowing interviews. ${ }^{2}$ A number of variants were distinguished for each vowel in the shift. Both (e) and (uh) have raised, backed, and lowered variants. Backing is the main direction of movement of both (e) and (uh). In each case, two degrees of backing were distinguished:

$$
\begin{aligned}
& {[\varepsilon]>\left[\varepsilon^{>}\right]>[\Lambda]} \\
& {[\Lambda]>\left[\Lambda^{>}\right]>[0]}
\end{aligned}
$$

Both variables also show lowering: [æ] for (e) and [a] for (uh). There are also some raised variants $\left[\varepsilon^{\wedge}\right]$ and $[\mathrm{I}]$ for (e) (the latter occurs particularly in get) and [a] and [U] for (uh). The lowest value for (ae) is [æ^]. The movement of the nucleus of (ae) has clearly been toward peripherality (Labov, Yaeger, \& Steiner, 1972), as the higher variants show fronting:

$$
\left[\mathfrak{x}^{\wedge}\right]>\left[\varepsilon^{\vee}\right]>[\varepsilon]>\left[\varepsilon^{<}\right]>[e]
$$

Two degrees of fronting were distinguished for (a):

$$
[\mathrm{a}]>[\mathrm{a}]>\left[\mathfrak{x}^{>}\right]
$$


TABLE 1. Percentage of advanced tokens of the five vowels for each combination of social category and sex (numbers of tokens in parentheses)

\begin{tabular}{|c|c|c|c|c|c|}
\hline & \multicolumn{2}{|c|}{ Boys } & \multicolumn{3}{|c|}{ Girls } \\
\hline & Jocks & Burnouts & Jocks & Bur & nouts \\
\hline (ae) & $39.7\left(\frac{211}{531}\right)$ & $35.3\left(\frac{101}{286}\right)$ & $62.2\left(\frac{244}{392}\right)$ & 62 & $\left(\frac{178}{287}\right)$ \\
\hline (a) & $21.4\left(\frac{117}{548}\right)$ & $22\left(\frac{77}{350}\right)$ & $33.8\left(\frac{152}{450}\right)$ & 38.2 & $\left(\frac{134}{350}\right)$ \\
\hline (oh) & $7.4\left(\frac{44}{598}\right)$ & $10.2\left(\frac{34}{333}\right)$ & $29.8\left(\frac{134}{450}\right)$ & 38.7 & $\left(\frac{131}{338}\right)$ \\
\hline (e) & $26.2\left(\frac{146}{557}\right)$ & $33.2\left(\frac{113}{340}\right)$ & $23.8\left(\frac{103}{433}\right)$ & 30.9 & $\left(\frac{103}{333}\right)$ \\
\hline (uh) & $24.6\left(\frac{122}{496}\right)$ & $35.3\left(\frac{65}{184}\right)$ & $25.8\left(\frac{94}{364}\right)$ & 43 & $\left(\frac{107}{249}\right)$ \\
\hline
\end{tabular}

(a) also showed some raising to $\left[\mathrm{a}^{\wedge}\right]$ and $[\Lambda]$. Finally, three degrees of fronting were distinguished for (oh):

$[0]>\left[\mathrm{o}^{<v}\right]>[\mathrm{a}]>[\mathrm{a}]$

(oh) also fronted occasionally to $[\Lambda]$. Extreme variants in the main direction of change were chosen for each of the variables to represent rule application. These extreme variants are:

(ae) nucleus $=[e]$ or $\left[\varepsilon^{<}\right]$, with or without offglide

(a) [æ] or $\left[a^{<}\right]$

(oh) $\left[a^{<}\right]$or $[a]$

(uh) [a] or [o]

(e) $[\Lambda]$ or $[\mathrm{U}]$

The two common social correlations for phonological variables in these data are with social category membership and sex. Sex and category affiliation are not simply additive but manifest themselves in a variety of ways among these changes. They interact in ways that are particularly revealing when seen in the context of the overall pattern of linguistic change. Table 1 contains a cross-tabulation by social category and sex of the percentage of advanced tokens for each vowel. Differences in the percentages shown in Table 1 between boys and girls and between Jocks and Burnouts for each of the changes are displayed in Figure 4: one line shows the lead of the girls over boys, whereas the other shows the lead of the Burnouts over the Jocks, for each of the changes in the Northern Cities Shift. As Figure 4 shows, the girls have the clearest lead in the oldest changes in the Northern Cities Chain Shift 


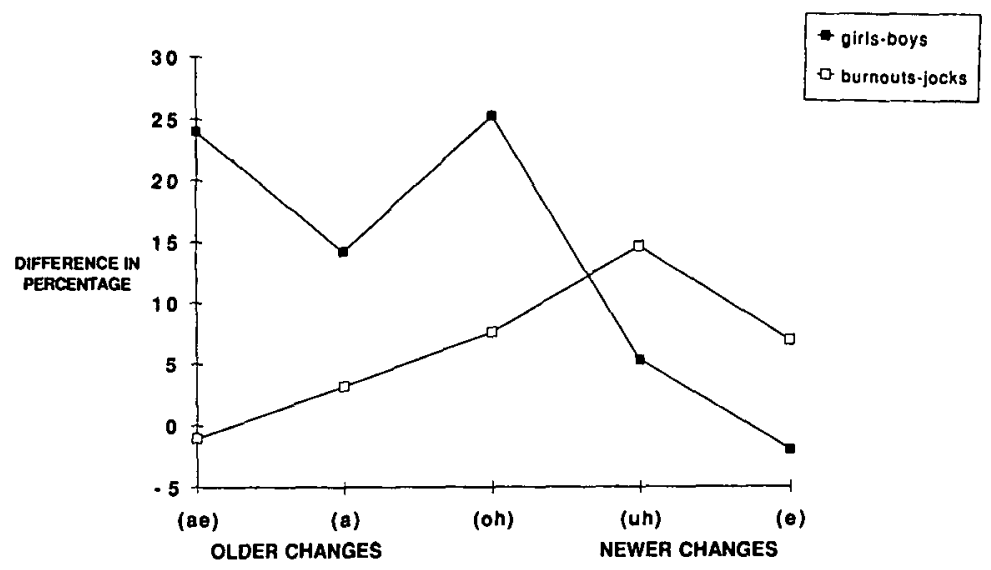

FIGURE 4. Contrast between girls and boys and between Burnouts and Jocks as differences in percentages when calculated for the combined data in Table 1.

TABLE 2. Significance (yes or no) of social constraints on the vowel changes that constitute the Northern Cities Chain Shift (pl-values of log-likelihood test calculated for each constraint separately using variable rule program on data of Table 1)

\begin{tabular}{lll}
\hline \hline & Sex & Social Category \\
\hline (ae) & yes $(p<.001)$ & no $(p<.77)$ \\
(a) & yes $(p<.001)$ & no $(p<.16)$ \\
$($ oh) & yes $(p<.0001)$ & yes $(p<.001)$ \\
(uh) & nob $(p<.04)$ & yes $(p<.001)$ \\
(e) & no $(p<.38)$ & yes $(p<.004)$ \\
\hline
\end{tabular}

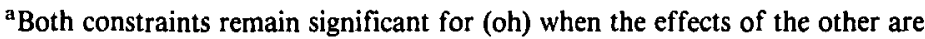
taken into account.

${ }^{b}$ The sex effect loses significance $(p<.19)$ for (uh) when social category is taken into account.

whereas social category differences take over in the later changes. Note that each line dips into negative figures once - at each end of the shift. The boys have a slight lead in the backing of (e) and the Jocks have a slight lead in the raising of (ae). The statistical significance of each of the differences is given in Table 2. A treatment of variation that views variables as markers would call the fronting of (ae) and (a) "sex markers," the backing of (uh) and (e) "social category markers," and the fronting of (oh) both.

In an earlier article, I expressed some puzzlement about the lack of sex differences in the backing of (uh), having expected a simple relation between sex and any sound change (Eckert, 1988). More careful examination of the backing of (uh), however, shows that a simplistic view of the relation between gender and sound change prevented me from exploring other ways in which 
gender might be manifested in variation. In fact, gender plays a role in four out of the five changes in the Northern Cities Chain Shift, although it correlates only with three out of five of the changes, and the role it plays is not the same for all changes.

As can be seen in Table 2 and Figure 4, the oldest change in the Northern Cities Chain Shift, the raising of (ae), shows no significant association with category membership in the sample as a whole. The same is true within each sex group taken separately (girls: $p<.96$; boys: $p<.22$ ). However, the girls lead by far in this change. The second change in the Northern Cities Shift, the fronting of (a), also shows only a sex difference, once again with the girls leading. The lack of category effect holds true within each sex group considered separately (girls: $p<.19$; boys: $p<.76$ ).

The lowering and fronting of (oh) shows a significant difference by both sex and social category, and these effects appear to operate additively in a variable rule analysis:

Overall tendency: 0.182

boys: 0.300 girls: 0.700

Jocks: 0.452 Burnouts: 0.548

When the sexes are separated, however, it turns out that the category difference is only significant among the girls $(p<.009)$ and not the boys $(p<$ $.14)$.

In the backing of (uh), category membership correlates significantly with backing for the population as a whole, with Burnouts leading, but sex does not. When each sex is considered separately, however, it is clear that the category difference is much greater among the girls. The backing of (e) shows a significant category difference, with the Burnouts leading, but no significant sex difference. In this case, when the two sexes are considered separately, the category difference is the same among the girls and among the boys.

Figure 5 compares the differences in the percentages in Table 1 between the Jocks and Burnouts, within the girls' and boys' samples separately. None of these differences is significant for (a) and for (ae). For (e) they are significant and identical for the two sexes. For (oh) and (uh), however, there is a clear tendency for there to be greater social category differentiation among the girls than among the boys.

These results throw into question general statements that women lead in sound change or that sex differences are indicative of sound change. In fact, in my data, the greatest sex differences occur with the older - and probably less vital - changes, involving (ae), (a), and (oh). I would venture the following hypotheses about the relation of gender to the older and the newer changes in these data. It appears that in both sets of changes, the girls are using variation more than the boys. In the case of the newer ones, the girls' patterns of variation show a greater difference between Jocks and Burnouts 


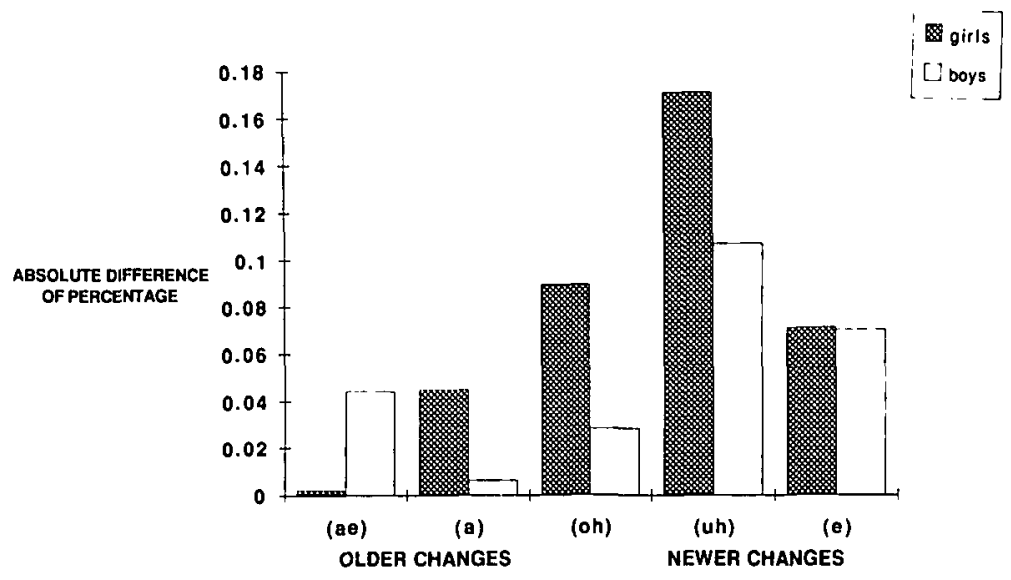

FIGURE 5. Absolute differences of percentages for Burnouts and Jocks, calculated separately for girls and boys (note that for (ae), Burnouts actually trail Jocks).

than do the boys'. In the case of the older ones, all girls are making far greater use than the boys of variables that are not associated with social category affiliation. I have speculated elsewhere that the newer changes, which are more advanced closer to the urban center, are ripe for association with counteradult norms (Eckert, 1987). The older changes, on the other hand, which have been around for some time and are quite advanced in the adult community, are probably not very effective as carriers of counteradult adolescent meaning, but they have a more generalized function associated with expressiveness and perhaps general membership. In both cases - the girls' greater differentiation of the newer changes and their greater use of older changes - the girls' phonological behavior is consonant with their greater need to use social symbols for self-presentation.

\section{CONCLUSIONS}

I would not, at this point, claim that the relation shown in these data between new and old changes is necessary, particularly in view of the fact that Labov (1984) found that women in Philadelphia led in new sound changes, whereas sex differences tended to disappear in older changes. It is apparent, then, that generalizations about the relation between sound change and gender are best deferred until more communities have been examined.

The first clear conclusion from these data is that sex and social category are not necessarily independent variables but that they can interact in a very significant way. It is the nature of that interaction, which occurs here with (oh) and (uh), that is of interest in this article. It is not the case with these phonological variables that there are large sex differences in one category and 
not in the other. In other words, sex is rarely more "salient" in one category than the other. One certainly cannot say that the boys and/or girls are asserting their gender identities through language more in one category than in the other. Rather, there are greater category differences in one sex group than the other. In other words, category membership is more salient to members of one sex than the other; girls are asserting their category identities through language more than are the boys. This is consonant with the fact that girls are more concerned with category membership than boys, as well as with the fact that girls must rely more on symbolic manifestations of social membership than boys. And this is, in turn, the adolescent manifestation of the broader generalization that women, deprived of access to real power, must claim status through the use of symbols of social membership.

These data make it clear that the search for explanations of sex differences in phonological variation should be redirected. All of the demographic categories that we correlate with phonological variation are more complex than their labels would indicate. Indeed, they are more complex than many sociolinguistic analyses give them credit for. Some analyses of sex differences have suffered from lack of information about women. But it is more important to consider that where most analyses have fallen short has been in the confusion of social meaning with the analyst's demographic abstractions.

NOTES

1. This is an oversimplification. Gender inequality imposes a canonical comparison, whereby higher and lower status accrue automatically to men and women, respectively. It is this inequality itself that leads to the tendency for intrasex comparisons and for the different terms on which men and women engage in these comparisons. Men tend to compare themselves with other men because women don't count, whereas women tend to compare themselves with other women with an eye to how that affects their relation to male-defined status. (My thanks to Jean Lave for helping me work out this tangle.)

2. The transcription of these data was done by Alison Edwards, Rebecca Knack, and Larry Diemer.

\section{REFERENCES}

Baroni, Maria Rosa, \& d'Urso, Valentina. (1984). Some experimental findings about the question of politeness and women's speech. Language in Society 13:67-72.

Bourdieu, Pierre, \& Boltanski, Luc. (1975). Le fétichisme de la langue. Actes de la recherche en sciences sociales 4:2-32.

Brown, Penelope. (1980). How and why women are more polite: Some evidence from a Mayan community. In Sally McConnell-Ginet, Ruth A. Borker, \& Nelly Furman (eds.), Women and language in literature and society. New York: Praeger. 111-136.

Brown, Penelope, \& Levinson, Steven. (1979). Social structure, groups and interaction. In Klaus R. Scherer \& Howard Giles (eds.), Social markers in speech. Cambridge: Cambridge University Press. 291-341.

(1987). Politeness. Cambridge: Cambridge University Press.

Cedergren, Henrietta. (1973). The interplay of social and linguistic factors in Panama. Ph.D. dissertation, Cornell University.

Clermont, Jean, \& Cedergren, Henrietta. (1978). Les "R" de ma mère sont perdus dans l'air. 
In Pierrette Thibault (ed.), Le français parlé: études sociolinguistiques. Edmonton, Alberta: Linguistic Research. 13-28.

Deuchar, Margaret. (1988). A pragmatic account of women's use of standard speech. In Jennifer Coates \& Deborah Cameron (eds.), Women in their speech communities. London: Longman. 27-32.

Eckert, Penelope. (1984). Age and linguistic change. In Jennie Keith \& David I. Kertzer (eds.), Age and anthropological theory. Ithaca: Cornell University Press. 219-233.

(1987). The relative values of variables. In Keith Denning, Sharon Inkelas, Faye McNairKnox, \& John Rickford (eds.), Variation in language: $N W A V-X V$. Stanford, Department of Linguistics. 101-110.

(1988). Adolescent social structure and the spread of linguistic change. Language in Society 17:183-207.

(1989a) Jocks and burnouts. New York: Teachers College Press.

(1989b). Social membership and linguistic variation. Paper presented at NWAVE, Duke University.

(1990). Cooperative competition in adolescent "girl talk." Discourse Processes 13:91-122.

Eckert, Penelope, Edwards, Alison, \& Robins, Lynne. (1985). Social and biological categories in the study of linguistic variation. Paper presented at NWAVE IV, Washington, DC.

Elshtain, Jean Bethke. (1981). Public man, private woman. Princeton: Princeton University Press.

Fox-Genovese, Elizabeth. (1988). Within the plantation household. Chapel Hill: University of North Carolina Press.

Gauchat, L. (1905). L'unité phonétique dans le patois d'une commune. In Festshrift Heinrich Morf. Halle: Max Niemeyer. 175-232.

Guy, G., Horvath, B., Vonwiller, J., Daisley, E., \& Rogers, I. (1986). An intonational change in progress in Australian English. Language in Society 15:23-52.

Haeri, Niloofar. (1989). Synchronic variation in Cairene Arabic: The case of palatalization. Paper presented at Linguistic Society of America Annual Meeting, Washington, DC.

Hindle, Donald. (1979). The social and situational conditioning of phonetic variation. Ph.D. dissertation, University of Pennsylvania.

Horvath, Barbara, \& Sankoff, David. (1987). Delimiting the Sydney speech community. Language in Society 16:179-204.

Labov, William. (1966). The social stratification of English in New York City. Washington, DC: Center for Applied Linguistics.

(1972a). Hypercorrection by the lower middle class as a factor in linguistic change. In William Labov (ed.), Sociolinguistic patterns. Philadelphia: University of Pennsylvania Press. 122-142.

(1972b). The linguistic consequences of being a lame. In William Labov (ed.), Sociolinguistic patterns. Philadelphia: University of Pennsylvania Press. 255-292.

(1972c). The social motivation of a sound change. In William Labov (ed.), Sociolinguistic patterns. Philadelphia: University of Pennsylvania Press. 1-42.

(1980). The social origins of sound change. In William Labov (ed.), Locating language in time and space. New York: Academic. 251-265.

(1984). The intersection of sex and social factors in the course of language change. Paper presented at NWAVE, Philadelphia.

Labov, W., Yaeger, M., \& Steiner, R. (1972). A quantitative study of sound change in progress. Report on NSF project No. 65-3287.

Laferriere, Martha. (1979). Ethnicity in phonological variation and change. Language 55:603-617.

Macaulay, R. K. S. (1977). Language, social class, and education. Edinburgh: University Press.

Maltz, Daniel, \& Borker, Ruth. (1982). A cultural approach to male-female miscommunication. In John J. Gumperz (ed.), Language and social identity. Cambridge: Cambridge University Press. 195-216.

Milroy, Lesley. (1980). Language and social networks. Oxford: Basil Blackwell.

Nichols, Patricia C. (1983). Linguistic options and choices for black women in the rural south. In Barrie Thorne, Cheris Kramarae, and Nancy Henley (eds.), Language, gender and society. Rowley, MA: Newbury House. 54-68.

Rickford, John. (1986). The need for new approaches to class analysis in sociolinguistics. Language and communication 6:215-221. 
Sacks, Karen. (1974). Engels revisited. In M. Rosaldo \& L. Lamphere (eds.), Women, culture and society. Stanford: Stanford University Press. 207-222.

Sankoff, David, \& Laberge, Suzanne. (1978). The linguistic market and the statistical explanation of variability. In David Sankoff (ed.), Linguistic variation: Models and methods. New York: Academic. 239-250.

Sattel, Jack W. (1983). Men, inexpressiveness, and power. In Barrie Thorne, Cheris Kramarae, \& Nancy Henley (eds.), Language, gender and society. Rowley, MA: Newbury House. 119-124.

Thibault, Pierrette. (1983). Equivalence et grammaticalisation. Ph.D. dissertation, Université de Montréal.

Trudgill, Peter. (1972a). Sex, covert prestige, and linguistic change in the urban British English of Norwich. Language in Society 1:179-195.

(1972b). The social differentiation of English in Norwich. Cambridge: Cambridge University Press.

Veblen, Thorstein. (1931). The theory of the leisure class. New York: Viking.

Wolfram, W. A. (1969). A sociolinguistic description of Detroit Negro speech. Washington, DC: Center for Applied Linguistics. 